\title{
Posterior Endoscope-Assisted Diskectomy Is an Effective Technique for Cervical Soft Disk Herniation
}

\author{
Derya Gündoğdu Karaoglư ${ }^{1}$ Omer Polat ${ }^{2} \quad$ Ozhan Merzuk Uckun $^{1} \quad$ Resul Karadeniz $^{1}$ Deniz Belen ${ }^{1}$ \\ Ali Dalgic ${ }^{1}$ \\ ${ }^{1}$ Ankara Numune Research and Training Hospital, Neurosurgery \\ Clinic, Ankara, Turkey \\ 2 Düzce University, School of Medicine, Department of Neurosurgery, \\ Düzce, Turkey \\ Address for correspondence Ali Dalgic, MD, Ragip Tuzun Mah, Gurler \\ Sk. No: 37/8, Yenimahalle, Ankara 06170, Turkey \\ (e-mail: alidalgic@yahoo.com).
}

J Neurol Surg A 2021;82:197-203.

\begin{abstract}
Keywords

- spine

- cervical disk herniation

- diskectomy

- endoscopy

- endoscope assisted
\end{abstract}

\section{Introduction}

Anterior cervical diskectomy and fusion (ACDF) is the most commonly used method for surgical treatment of cervical disk herniation. This method is an extension of the interbody fusion method, first described by Robinson and Smith and revised by Cloward in $1958 .{ }^{1}$ However, this method may lead to long-term sequelae such as dysphagia, recurrent laryngeal nerve injury, and delayed bone fusion. ${ }^{2,3}$

The typical complications of ACDF include graft-related problems, pseudoarthrosis, adjacent-segment disease (ASD), fusion failure, and limited cervical range of motion. ${ }^{4-7}$ Posterior keyhole laminoforaminotomy was developed to prevent delayed bone fusion and adjacent-segment disease. ${ }^{8}$

received

February 8, 2019

accepted after revision

July 30, 2019

published online

January 6, 2021
Posterior cervical microdiskectomy has long been used for soft cervical disk herniation with foraminal localization. However, the need for muscle dissection is an important disadvantage of this method. Although the use of speculumlike retractors helps minimize muscle injury, muscle dissection is still required for microdiskectomy. Surgical field illumination by microscope and working through a tube are other disadvantages of using tube-like retractors. Recent advances in endoscopic technology and optic systems allow placement of a camera and a light source inside a tubular retractor system that provides sufficient surgical field illumination and the leverage to work with both hands.

Less surgical trauma is a major advantage of endoscopic surgery because it minimizes muscle dissection, reduces the

(c) 2021. Thieme. All rights reserved. Georg Thieme Verlag KG, Rüdigerstraße 14,

DOI https://doi.org/ 10.1055/s-0040-1709166. ISSN 2193-6315. 
need for blood transfusion, promotes early mobilization, and allows early discharge and return to work. The absence of a fusion requirement and preservation of the spinal motion segment are important advantages. Hence reduced workforce loss and the absence of surgical implant material also make endoscopic spinal surgical interventions cost effective. ${ }^{2,4-7}$

In this study, we reviewed retrospectively the clinicoradiologic data of patients with soft cervical disk herniation with foraminal localization who underwent percutaneous endoscope-assisted cervical diskectomy.

\section{Materials and Methods}

Clinical data pertaining to 30 patients who underwent posterior endoscope-assisted cervical diskectomy (PEACD) between June 2011 and January 2017 were reviewed retrospectively. The diagnosis of cervical disk hernia was based on radicular symptoms (pain, sensory deficit, or weakness) and radiologic signs. Magnetic resonance (MR) imaging and/or computed tomography (CT) were performed to assess the suitability of patients for PEACD. Patients with a soft disk herniation with a lateral/foraminal location on cervical MR imaging and no osteophytes causing serious compression on cervical CT were selected as appropriate candidates. PEACD was performed for patients who had soft disk herniation at the foraminal level ( $\mathbf{F i g . ~ 1 A , ~ B ) . ~}$

Those with calcified disks accompanied by osteophytes, midline disk herniation, disease involving two or more disk segments, and patients with recurrent herniation were considered unsuitable for the PEACD approach and were excluded. In three patients (10\%), the operation was switched to a microdiskectomy procedure; hence these three patients were also excluded from the study. Of these, one patient had intensive and sustained hemorrhage from the epidural venous plexus; the second patient had an osteophyte with disk herniation that was difficult to remove with the endoscopic system; and in the third patient, a cerebrospinal fluid (CSF) leak was noted during placement of the tubes.

All operations were performed by a senior surgeon (A.D.). Data pertaining to preoperative, postoperative, 1-week, and final follow-up examinations were obtained for the remaining 27 patients. The visual analog scale (VAS) and Prolo Functional Economic Outcome Rating Scale scores were compared, and the MacNab scores in the final control examination were recorded. In addition, radiologic examinations comparing spinal alignment and function at the motion segment before the operation and at follow-up were reviewed to identify development of ASD.

\section{Surgical Technique}

All patients underwent surgery under general anesthesia in a prone position, with the head stabilized with a horseshoe head rest and the neck maintained in slight flexion. After preoperative determination of the true level by radiographs, the interlaminar space was accessed using dilator tubes, $\sim 2 \mathrm{~cm}$ lateral to the midline. A 15-mm working cannula was placed (Easy-Go System, Karl Storz, Tuttlingen, Germany). Keyhole foraminot- omy was performed from the junction of the lamina and the facet using a high-speed drill. The foraminotomy involved one third from the cranial lamina-facet junction and two thirds from the caudal lamina-facet junction. The ligamentum flavum and the epidural venous plexus were coagulated and excised, and the dural sac and nerve root were exposed. The nerve hook and the sequestrated disk fragment were removed from the nerve root's axilla with the help of a microdissector (-Videos 1 and 2 ).

\section{Video 1}

Operative video showed a case with C6-7 disc herniation on the right side. It should be paid attention as followed that firstly, partial hemilaminectomy on lower lamina (C7) is enough for sequestrectomy; secondly, ligamantum flavum was coagulated by bipolar at the beginning, before removed for avoiding of bleeding of epidural venous plexus. Online content including video sequences viewable at: https://www.thieme-connect. com/products/ejournals/html/10.1055/s-00401709166.

\section{Video 2}

The case was presented by MRI images with $\sim$ Figs. 1 and 2. Video showed that sequestrectomy can be performed via limited hemilaminectomy (only T1) by endoscopeassisted system. Online content including video sequences viewable at: https://www.thieme-connect. com/products/ejournals/html/10.1055/s-00401709166.

\section{Results}

Sixteen patients (59.2\%) were male, and 11 (40.8\%) were female; the mean age of the patients was 40.9 years (range: 18-56 years). The mean duration of follow-up was 35.1 months. All patients had unilateral arm pain; 16 patients $(59.2 \%)$ had left arm pain; 11 (40.8\%) had right arm pain. Seven patients (25.9\%) had pain only, whereas $20(74.1 \%)$ had associated sensory loss, and $6(22.2 \%)$ had associated weakness. The disk herniation level was C5-C6 in 15 (55.5\%), C6-C7 in 11 (40.7\%), and C7-T1 in one patient (3.7\%). Among these, 16 (59.2\%) had extruded disk herniation; 11 (40.2\%) had sequestrated disk herniation, as seen on MR imaging. - Table 1 summarizes the demographic characteristics of the study population.

The mean preoperative VAS score was 8.6 (range: 7-10), and the mean preoperative Prolo scale score was 2.5 (range: 2-5) (-Table 2). The mean operative time was 82.6 minutes (range: 55-95 minutes); mean intraoperative blood loss was $171.5 \mathrm{~mL}$ (range: $130-190 \mathrm{~mL}$ ). Two patients developed a perioperative CSF leak from the axillary region 

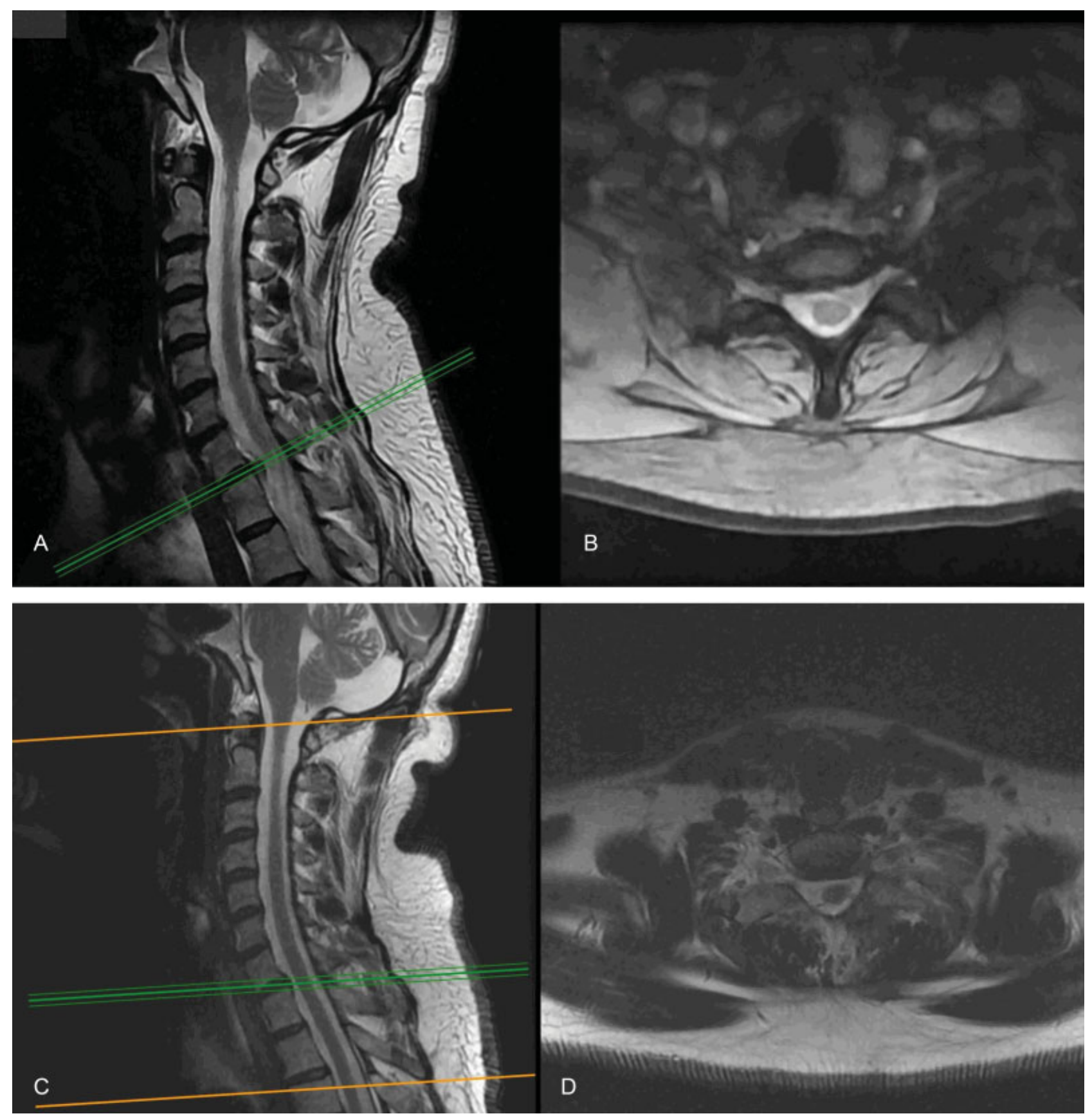

Fig. 1 (A) Preoperative T2-weighted sagittal magnetic resonance (MR) image and (B) axial MR image showing a soft disk herniation located at the left foramina. Postoperative MR images, (C) sagittal and (D) axial, plane show the disk has been removed.

of nerve roots that was treated only with fibrin glue. All patients were discharged on postoperative day 1 . The mean VAS score at the first control visit (1 week) was 2.1 (range: 0-4). At the final control examination, the mean VAS score was 0.81 (range: $0-3$ ), and the mean Prolo score was 4.5 (range: $3-5$ ) (-Table 2). The mean MacNab scores at the control examination were as follows: $62.9 \%$, excellent; $25.9 \%$, good; 7.4\%, moderate; and 3.7\%, poor (-Table 3 ).

During the follow-up period, one patient developed a recurrence at the operated segment. This patient had a poor MacNab score, VAS score of 6, and a Prolo score of 3. The patient had undergone surgery 16 months earlier at the C5-C6 level and had experienced alleviation of pain after surgery; however, there was recurrence of severe pain over the preceding 3 months, and ACDF was performed at the same level. Review of the MR images of other patients revealed no newly developed herniation either at the operated level or at the adjacent disk segments. Furthermore, there were no radiologic signs of adjacent-segment degeneration such as stenosis, loss of disk height, or calcified ligament at the follow-up examination (-Fig. 1C, D).

\section{Discussion}

ACDF has been used since the 1950s and is currently accepted as the standard approach. ${ }^{1,3}$ However, ACDF is known to be 
Table 1 Demographic and clinical characteristics of the study population

\begin{tabular}{|l|l|}
\hline Age, $\boldsymbol{y}$ (range) & $40.9(18-56)$ \\
\hline Sex, $\boldsymbol{n}(\%)$ & \\
\hline Male & $16(59.2)$ \\
\hline Female & $11(40.8)$ \\
\hline Radiologic finding, $\boldsymbol{n}(\%)$ & \\
\hline C5-C6 disk herniation & $15(55.5)$ \\
\hline C6-C7 disk herniation & $11(40.7)$ \\
\hline C7-T1 disk herniation & $1(3.7)$ \\
\hline Extruded disk & $16(59.2)$ \\
\hline Sequestrated disk & $11(40.2)$ \\
\hline Clinical condition, $\boldsymbol{n}(\%)$ & \\
\hline Only arm pain & $7(25.9)$ \\
\hline Arm pain + sensory loss & $20(74.1)$ \\
\hline Arm pain + sensory loss + motor loss & $6(22.2)$ \\
\hline Follow-up, mo (range) & $35.1(3-41)$ \\
\hline
\end{tabular}

Table 2 VAS and Prolo economic scores of patients at various time points: preoperative, postoperative first week, and final control examination

\begin{tabular}{|l|l|l|}
\hline & $\begin{array}{l}\text { VAS } \\
\text { (range) }\end{array}$ & $\begin{array}{l}\text { Prolo scale } \\
\text { (range) }\end{array}$ \\
\hline Preoperative & $8.1(7-10)$ & $2.5(2-5)$ \\
\hline $\begin{array}{l}\text { Postoperative } \\
\text { first week }\end{array}$ & $2.1(0-5)$ & \\
\hline Follow-up & $0.81(0-3)$ & $4.5(3-5)$ \\
\hline
\end{tabular}

Abbreviation: VAS, visual analog scale.

Table 3 MacNab scores at the final examination

\begin{tabular}{|l|l|l|}
\hline & $\boldsymbol{n}$ & MacNab, \% \\
\hline Excellent & 17 & 62.9 \\
\hline Good & 7 & 25.9 \\
\hline Fair & 2 & 7.4 \\
\hline Poor & 1 & 3.7 \\
\hline
\end{tabular}

associated with some distinct early and late complications. The early complications include neurologic deterioration, dysphagia, esophageal perforation, hoarseness, vascular injury, and postoperative hematoma. ${ }^{2,3,9}$ Hoarseness largely results from edema and intubation; however, a small percentage of patients may develop permanent hoarseness due to recurrent laryngeal nerve injury. In a large case-series report by Flynn, the incidence of permanent recurrent laryngeal nerve injury was $2 \% .{ }^{9}$ Vascular injury is another important, albeit rare, complication of anterior cervical surgery that most commonly involves the carotid artery and the jugular vein. ${ }^{2}$ Embolic stroke may also occur secondary to carotid atheroma plaques as a result of excessive carotid artery manipulation. ${ }^{10}$ Esophageal perforation is associated with a high morbidity and mortality; the estimated risk of esophageal perforation during anterior cervical diskectomy is $0.25 \%$. Despite its rarity, this complication may have catastrophic consequences such as mediastinitis, abscess, or tracheoesophageal fistula. ${ }^{11}$ Horner's syndrome is another rare complication that tends to be transient; however, $<1 \%$ of patients may develop permanent ptosis. $^{2}$

Dysphagia is the most common early complication of anterior cervical surgery. Esophageal and tracheal retraction may cause edema, hemorrhage, and denervation leading to dysphagia; in addition, infection may also cause this complication. Although dysphagia tends to improve over several days, persistent dysphagia is an important problem that impairs quality of life. ${ }^{2,3,11}$

Implants used during ACDF are a major cause of late complications. The most common ones include subsidence, dislocation, or failure of fusion of the cage or graft placed in the intervertebral disk space. ${ }^{4}$ The reported incidence of graft dislocation is 2 to $8 \% .^{5}$ As an additional complication, failure of fusion was reported in $5 \%$ of single-level and $15 \%$ of multilevel ACDFs. ${ }^{12}$

In the last 2 decades, several studies have focused on ASD following ACDF. In a study by Goffin et al, radiologic ASD was observed in $92 \%$ of patients irrespective of the presence or absence of symptoms. ${ }^{13}$ In the study by Hilibrand et al, 25\% patients who underwent ACDF developed symptomatic ASD over a 10 -year follow-up; $2.9 \%$ of patients required repeat surgery each year. ${ }^{14}$ Many studies found that ACDF may cause biomechanical changes in adjacent segments that may lead to ASD. ${ }^{6,7}$

Motion-preserving treatment methods were proposed to prevent ASD. ${ }^{15}$ Among these, disk prosthesis was shown to preserve motion, although development of heterotopic ossification (HO) and spontaneous fusion was documented in some long-term case series. HO refers to calcified longus coli muscles after disk prosthesis placement that causes neck pain. Murrey et al reported the outcomes of 117 patients in whom disk prosthesis was implanted; 9.4\% developed HO and $2.9 \%$ developed spontaneous fusion over a 2-year followup. ${ }^{16}$ In a study by Leung et al $(n=100)$, the incidence of $\mathrm{HO}$ was $17.8 \%$ and that of spontaneous fusion was $11 \%$ over a 1-year follow-up period. ${ }^{17}$ Spontaneous fusion is an inevitable natural phenomenon, especially in degenerative disk diseases, even with the use of a motion-preserving disk prosthesis. The complications of ACDF previously described make it a particularly risky procedure for patients involved in certain professions, such as singers, soldiers, and athletes. For patients in these professions, posterior approaches have been used increasingly because of socioeconomic factors. ${ }^{18}$

Indeed, posterior cervical approach predates the anterior cervical approach; however, the posterior cervical approach entails more extensive muscle dissection that increases the incidence of postoperative neck pain. The rapid advances in surgical tools and the use of the microscope have obviated the need for extensive muscle dissection. These developments facilitated further refinement of posterior approaches. In the 1980s, Casotto and Buoncristiani, 
Fager, and Epstein et al popularized a method referred to as a "keyhole" laminoforaminotomy; the reported success rates with this method are as high as $90 \%{ }^{19-21}$

The primary advantage of minimally invasive posterior keyhole foraminotomy is that it minimizes muscle injury and decreases the incidence of postoperative pain. This in turn reduces the length of the hospital stay and facilitates an early return to work. Fusion is not required in posterior keyhole foraminotomy. This eliminates the risk of both implantrelated complications and pseudoarthrosis. In addition, the absence of fusion allows natural aging of the spine and reduces the risk of ASD. ${ }^{8}$

In many previous reports, posterior cervical diskectomy performed using minimally invasive approaches was regarded as motion-preserving surgery. ${ }^{22,23}$ Kim and colleagues $^{24}$ compared preoperative disk height and sagittal alignment with those at 12-month follow-up in patients who underwent posterior cervical diskectomy. They found neither a significant reduction in disk height nor a progression to kyphosis. The relatively short follow-up was a limitation of their study, and they stressed the need for studies with a longer follow-up. However, our study failed to reveal any additional degenerative alterations in adjacent disk spaces over a follow-up period of 24.7 months.

The rapid advances in endoscopic systems offer surgical field illumination and image quality equivalent to those of microscopic images. ${ }^{25}$ An endoscope-assisted system was used in our study. The greatest advantage of this system is that it allows the surgeon to use both hands with the concomitant ease of manipulation, similar to that in microsurgery. While tubular retractor systems cannot provide sufficient microscope light to illuminate the surgical field, the light source and camera, which is located at the tip of the tubular system in the endoscope-assisted system, provides good illumination and improves the image quality. This advantage facilitated the switch from the microscope to endoscopic systems. Although a learning curve exists for endoscopic approaches, no clinically discernible differences exist in the hands of experienced surgeons. ${ }^{26}$ Studies showed no significant difference between the clinical success rates achieved with minimally invasive and microscopic approaches for posterior cervical diskectomy. ${ }^{27,28}$

Fessler and Khoo compared 25 endoscopic cases and 25 microscopic keyhole foraminotomy cases and found no significant differences between the two methods with respect to amelioration of radicular and neck pain; radicular pain and neck pain was completely eliminated in $92 \%$ and $87 \%$ of the endoscopic cases, respectively, and $88 \%$ and $89 \%$ of the microscopic keyhole foraminotomy cases, respectively. ${ }^{23}$ Kim and Kim used microscopic keyhole foraminotomy in 19 patients and endoscope-assisted keyhole foraminotomy in 22 cases, and they found a marked reduction in the duration of hospital stay, postoperative analgesic use, and intraoperative bleeding in endoscopic cases; however, there were no significant between-group differences with respect to clinical outcomes. ${ }^{28}$ The endoscope-assisted system has also been used to decompress foraminal stenosis in patients with cervical radiculopathy. ${ }^{29}$
The endoscope-assisted method is typically used for foraminal soft disks; patients with spinal cord compression and facet joint degeneration or calcified disks are excluded. ${ }^{24}$ Ruetten et al included lateral disks causing unilateral radiculopathy and excluded patients with instability and deformity, medially localized disks, or posterior longitudinal ligament calcification. ${ }^{30}$ We also included lateral or foraminal soft disks causing radiculopathy and excluded disks accompanied by osteophytes, midline disk herniation, or disk disease involving two or more segments.

In the cervical regions, nerve roots usually exit the foramina at an almost right angle at the level of the disk space. Therefore, the herniated disk and the adjacent osteophytes are covered by the nerve root. Because the disk space and the herniated disk are generally close to the axilla, it may be removed via the nerve root's axilla. Because the disk tissue has a relatively soft texture, use of a nerve hook to pull it out with gentle retraction is usually sufficient to remove it. However, it is very hard to remove osteophytes using the same technique because it necessitates exposure of the nerve root and/or the dural sac, which may cause severe complications. Moreover, removing osteophytes located in the upper end plate with keyhole foraminotomy involves even more serious risks. In such cases, nerve root decompression can be achieved by extended foraminotomy. Burkhardt et al reported favorable outcomes of endoscopic posterior foraminotomy in patients with foraminal stenosis and also showed successful results with multilevel stenosis; moreover, the technique can be used for recurrent cervical disk herniation. ${ }^{31}$ Although posterior procedures represent an indirect decompression because osteophyte compression is located anteriorly, posterior endoscopic foraminotomy is an effective alternative to the anterior approach in suitable cases.

Ruetten et al performed cervical diskectomy with full endoscopic foraminotomy in 89 patients and reported a success rate of $96.6 \%$ during a $24-$ month follow-up. They also reported an improvement in early VAS scores by 1.73 points. Having used a 5.9-mm working cannula and a 25-degree camera, they stated that full endoscopic posterior cervical approaches do not directly aim at the disk as they do in lumbar pathologies when laminoforaminotomy is performed, even though minimally. They stated that the goal of using posterior endoscopic approaches is to achieve satisfactory results by avoiding surgical trauma with a good view of the surgical field; they further added that the currently used term "full endoscopic" falls short in defining the posterior cervical approach.

Ruetten and colleagues pointed out that the term "full endoscopic" approach is used for transdiskal methods that do not require bone resection, as do lumbar and anterior cervical approaches. ${ }^{30,32}$ However, cervical disk herniation is below a nerve root and can be removed from the axillary route. Therefore, keyhole foraminotomy provides an important step for safe removal of the disk. The PEACD approach ensures minimal muscle injury and confers the advantages of a minimally invasive approach; it allows a direct view of the nerve root via keyhole foraminotomy and minimizes the risk of nerve root injury by providing an opportunity to work with both hands.

CSF leakage during cervical disk removal via the posterior approach usually occurs as a result of dural injury at the 
nerve root's axilla. Dural repair using primary suture at the axilla is typically challenging. Futhermore, the possibility of injury to nerve fibers during suturing should also be considered. Some reports described dural repair performed with tools (like the U-clip) that are used during abdominal laparoscopic procedures. ${ }^{33}$ However, it is difficult to close a dural tear at the axillary region due to the inappropriate angle. Likewise, muscular and/or fatty tissue patches were used for dural repair. ${ }^{34}$ However, use of these grafts at the axilla of nerve roots can cause irritation of the nerve root.

Three patients in our series sustained dural injury. One of them developed dural injury during placement of dilator tubes owing to the dilator tube entering the canal through an interlaminar space; therefore, the procedure was switched to microdiskectomy, considering the anticipated need for wide decompression with clear visualization of the nerve root and the spinal cord. In the other two cases, the dural tear was at the nerve root axilla; these two patients were treated successfully with fibrin tissue glue alone.

The learning curve of endoscopic spinal procedures is, among others, related to the two-dimensionality of the endoscopic image. ${ }^{35}$ The initial three patients operated on in this case series required a switch to microdiskectomy. In the first case, the dilatation tube was inserted in the spinal canal, and we performed microscopic exposition and decompression of the spinal cord. The second case had intensive bleeding, and the last one had a hard disk herniation and osteophytes. We think that problem-solving ability increases with experience: (1) cauterization of veins was patiently and gradually performed for control of bleeding that started during removal of the flavum and subsequently from the epidural venous plexus. (2) Extended foraminotomy was also performed for moderate stenosis and/or including osteophytes in the other cases. The switch to microdiskectomy was not required in the final 20 patients in this series.

\section{Conclusion}

PEACD is a minimally invasive method that provides surgeons with the ability to use both hands, increasing manual dexterity during surgical maneuvers. Although ACDF is regarded as the standard approach for treatment of cervical disk herniation, posterior cervical diskectomy is as effective as the anterior approach when appropriate patients with soft disk herniation at a lateral and/or foraminal localization are selected. This was a single-center study involving a single surgeon, which is the main study limitation. Further prospective and randomized studies are required to compare the outcomes with those of anterior approaches.

\section{Conflict of Interest}

None declared.

\section{References}

1 Cloward RB. The anterior approach for removal of ruptured cervical disks. J Neurosurg 1958;15(06):602-617

2 Fountas KN, Kapsalaki EZ, Nikolakakos LG, et al. Anterior cervical discectomy and fusion associated complications. Spine 2007;32 (21):2310-2317
3 Wilson JR, Radcliff K, Schroeder G, et al. Frequency and acceptability of adverse events after anterior cervical discectomy and fusion: a survey study from the Cervical Spine Research Society. Clin Spine Surg 2018;31(05):E270-E277

4 Pirkle S, Kaskovich S, Cook DJ, Ho A, Shi LL, Lee MJ. Cages in ACDF are associated with a higher nonunion rate than allograft: a stratified comparative analysis of 6130 patients. Spine 2019;44 (06):384-388

5 Noordhoek I, Koning MT, Jacobs WCH, Vleggeert-Lankamp CLA. Incidence and clinical relevance of cage subsidence in anterior cervical discectomy and fusion: a systematic review. Acta Neurochir (Wien) 2018;160(04):873-880

6 Carrier CS, Bono CM, Lebl DR. Evidence-based analysis of adjacent segment degeneration and disease after ACDF: a systematic review. Spine J 2013;13(10):1370-1378

7 Wang F, Hou HT, Wang P, Zhang JT, Shen Y. Symptomatic adjacent segment disease after single-lever anterior cervical discectomy and fusion: incidence and risk factors. Medicine (Baltimore) 2017;96(47):e8663

8 Acikbas SC, Ermol C, Akyuz M, Tuncer R. Assessment of adjacent segment degeneration in and between patients treated with anterior or posterior cervical simple discectomy. Turk Neurosurg 2010;20(03):334-340

9 Flynn TB. Neurologic complications of anterior cervical interbody fusion. Spine 1982;7(06):536-539

10 Graffeo CS, Puffer RC, Wijdicks EF, Krauss WE. Delayed cerebral infarct following anterior cervical diskectomy and fusion. Surg Neurol Int 2016;7:86

11 Halani SH, Baum GR, Riley JP, et al. Esophageal perforation after anterior cervical spine surgery: a systematic review of the literature. J Neurosurg Spine 2016;25(03):285-291

12 Veeravagu A, Cole T, Jiang B, Ratliff JK. Revision rates and complication incidence in single- and multilevel anterior cervical discectomy and fusion procedures: an administrative database study. Spine J 2014;14(07):1125-1131

13 Goffin J, van Loon J, Van Calenbergh F, Plets C. Long-term results after anterior cervical fusion and osteosynthetic stabilization for fractures and/or dislocations of the cervical spine. J Spinal Disord 1995;8(06):500-508; discussion 499

14 Hilibrand AS, Carlson GD, Palumbo MA, Jones PK, Bohlman HH. Radiculopathy and myelopathy at segments adjacent to the site of a previous anterior cervical arthrodesis. J Bone Joint Surg Am 1999;81(04):519-528

15 Xu S, Liang Y, Zhu Z, Qian Y, Liu H. Adjacent segment degeneration or disease after cervical total disc replacement: a meta-analysis of randomized controlled trials. J Orthop Surg Res 2018;13(01):244

16 Murrey D, Janssen M, Delamarter R, et al. Results of the prospective, randomized, controlled multicenter Food and Drug Administration investigational device exemption study of the ProDisc- $C$ total disc replacement versus anterior discectomy and fusion for the treatment of 1-level symptomatic cervical disc disease. Spine J 2009;9(04):275-286

17 Leung C, Casey AT, Goffin J, et al. Clinical significance of heterotopic ossification in cervical disc replacement: a prospective multicenter clinical trial. Neurosurgery 2005;57(04):759-763; discussion 759-763

$18 \mathrm{Kim} \mathrm{CH}$, Chung CK, Kim HJ, Jahng TA, Kim DG. Early outcome of posterior cervical endoscopic discectomy: an alternative treatment choice for physically/socially active patients. J Korean Med Sci 2009;24(02):302-306

19 Casotto A, Buoncristiani P. Posterior approach in cervical spondylotic myeloradiculopathy. Acta Neurochir (Wien) 1981;57 (3-4):275-285

20 Fager CA. Posterolateral approach to ruptured median and paramedian cervical disk. Surg Neurol 1983;20(06):443-452

21 Epstein JA, Janin Y, Carras R, Lavine LS. A comparative study of the treatment of cervical spondylotic myeloradiculopathy. Experience with 50 cases treated by means of extensive laminectomy, 
foraminotomy, and excision of osteophytes during the past 10 years. Acta Neurochir (Wien) 1982;61(1-3):89-104

22 Coric D, Adamson T. Minimally invasive cervical microendoscopic laminoforaminotomy. Neurosurg Focus 2008;25(02):E2

23 Fessler RG, Khoo LT. Minimally invasive cervical microendoscopic foraminotomy: an initial clinical experience. Neurosurgery 2002; 51(5, Suppl):S37-S45

$24 \mathrm{Kim} \mathrm{CH}$, Kim KT, Chung CK, et al. Minimally invasive cervical foraminotomy and diskectomy for laterally located soft disk herniation. Eur Spine J 2015;24(12):3005-3012

25 Won S, Kim CH, Chung CK, et al. Comparison of cervical sagittal alignment and kinematics after posterior full-endoscopic cervical foraminotomy and discectomy according to preoperative cervical alignment. Pain Physician 2017;20(02):77-87

26 Burkhardt BW, Wilmes M, Sharif S, Oertel JM. The visualization of the surgical field in tubular assisted spine surgery: is there a difference between HD-endoscopy and microscopy? Clin Neurol Neurosurg 2017;158:5-11

27 Burkhardt BW, Oertel JM. The learning process of endoscopic spinal surgery for degenerative cervical and lumbar disorders using the EasyGO! system. World Neurosurg 2018;119:479-487

$28 \mathrm{Kim}$ KT, Kim YB. Comparison between open procedure and tubular retractor assisted procedure for cervical radiculopathy: results of a randomized controlled study.J Korean Med Sci 2009;24(04):649-653
29 Oertel JM, Philipps M, Burkhardt BW. Endoscopic posterior cervical foraminotomy as a treatment for osseous foraminal stenosis. World Neurosurg 2016;91:50-57

30 Ruetten S, Komp M, Merk H, Godolias G. Full-endoscopic cervical posterior foraminotomy for the operation of lateral disc herniations using 5.9-mm endoscopes: a prospective, randomized, controlled study. Spine 2008;33(09):940-948

31 Burkhardt BW, Müller S, Oertel JM. Influence of prior cervical surgery on surgical outcome of endoscopic posterior cervical foraminotomy for osseous foraminal stenosis. World Neurosurg 2016;95:14-21

32 Ruetten S, Komp M, Merk H, Godolias G. A new full-endoscopic technique for cervical posterior foraminotomy in the treatment of lateral disc herniations using 6.9-mm endoscopes: prospective 2year results of 87 patients. Minim Invasive Neurosurg 2007;50 (04):219-226

33 Oertel JM, Burkhardt BW. Full endoscopic treatment of dural tears in lumbar spine surgery. Eur Spine J 2017;26(10):2496-2503

34 Müller SJ, Burkhardt BW, Oertel JM. Management of dural tears in endoscopic lumbar spinal surgery: a review of the literature. World Neurosurg 2018;119:494-499

35 Burkhardt BW, Oertel JM. Endoscopic spinal surgery using a new tubular retractor with $15 \mathrm{~mm}$ outer diameter. Br J Neurosurg 2019;18:1-8 